\title{
Brand Perceptions among School Children
}

\author{
Wan Edura Wan Rashid \\ Faculty of Office Management and Technology, Universiti Teknologi MARA \\ 40450, Shah Alam, Selangor, Malaysia \\ Tel:+6-03-55435549 E-mail:wan_edura@yahoo.com
}

Azura Omar

Faculty of Business Administration, Kulliyahh of Economics and Management

Tel:+6-03-61694733Ｅ-mail: azura_omar@iiu.edu.my

Kamaruzaman Jusoff (Corresponding author)

Yale's Center for Earth Observation, Tropical Resources Institute

School of Forestry \& Environmental Studies, 370 Prospect Street

New Haven, CT 06511, USA

Tel: (203) 432-3772 (voice) E-mail: jusoff.kamaruzaman@yale.edu

\begin{abstract}
This paper aims to explore the perception of children towards brand consciousness by using drawings and open-ended questions. A total of 20 primary school were requested to draw what they think about two statements given related to a person with branded materials and a person without branded materials. After drawing, respondents were personally interviewed regarding belongings of branded goods with cheerfulness, friendship, behaviour characters and desire for belongings. Results from the analysis of the drawings and interviews indicate that that there are significant differences in the children perception of someone with or without branded materials. Based on these findings, one hypothesis was proposed about perception of children with regard the knowledge of brand awareness.
\end{abstract}

Keywords: Brand, Consciousness, Perceptions, School Children, Consumer Socialization.

\section{Introduction}

There is a growing interest in the role played by brands in the everyday life of consumers, including that of children. According to Achenreiner (2003), brand consciousness amongst children is on the increase. It has in fact become an integral part of the way young consumers define themselves and how they would like others to view them. Notwithstanding this important trend, there has been very little research done on the relationship between children's cognitive development and the consumption values that branded items may represent (John, 1999). This study has adopted John's (1999) model of consumer socialization of children to explore children's perceptions towards brands in general. More specifically, the study looks at the differences in the children's perception of someone who possess a lot of branded goods as opposed to another who does not have or has very few of these items.

\section{Methodology}

The present study adopts a drawing method (Chan, 2004) to investigate children's perception of brands and their potential impact on the identity of brand users. Drawing as a research method has been used for more than 100 years for a number of research purposes (Thomas and Silk,1990; Matthew, 1999). The use of the drawing method in research involving children, irrespective of the purposes of the research, is warranted based on the critical premise that children hold visual images in their heads (Rossiter, 1976; Zaltman, 1997). In fact, Zaltman (1997) notes that children may hold most of the information in their memory in visual form. Also, when children are asked to draw, and if given the freedom, will draw what they value, what they like and what is satisfying to them (Dennis, 1966; Golomb, 1992).

The use of drawing methods in the research involving children, irrespective of the purposes of the research, are warranted based on the critical premise that children hold visual images in their heads (Rossiter, 1976; Zaltman, 1997). In fact, according to Zaltman (1997) perhaps children may hold most of the information in their memory in visual form. Also, when children are asked to draw, and if given the freedom, children will draw what they value, what they like, and what is satisfying to them (Dennis, 1966; Golomb, 1992). As Dennis (1996,) explained, children asked to draw foods 
"will draw favorite foods, not those they dislike", and children asked to draw plants "will draw those bearing flowers or fruits, not noxious weeds".

The sample consisted of 20 primary school students in which they were recruited through personal contacts. The age profile of the sample was between 10 to 12 years old. The gender split was fairly even with 11 boys and 9 girls from middle income class. Before the interview session started, the respondents were briefly informed the objectives of this study and how the interviews will be conducted.

Each participant was given a piece of plain white drawing block $(274 \mathrm{~mm} \times 375 \mathrm{~mm})$, a black $2 \mathrm{~B}$ pencil and an eraser. Every piece of paper had two blank boxes of equal size. On top of each box was a statement - on the left "A person with a lot of branded goods" (Picture A) and on the right "A person without a lot of branded goods" (Picture B). Specific instructions were also given to the participants. All drawings were analyzed by a female counselor.

Following the drawing sessions, the participants were interviewed independently. Each interview took not more than 20 minutes and was conducted in Bahasa Melayu. All were recorded (with permission from the respondents), transcribed and translated into English. The interview transcripts were than analyzed using content analysis.

\section{Results and discussion}

Table I summarizes the visual substances in the drawings of the participants in relation to Picture A (a person with a lot of branded goods) and Picture B (a person without of branded goods. Eighteen pictures with at least one branded item in each 24 different brand names appearing in Picture altogether. The highest frequently occurring brands were Nokia, Acer, Adidas, Asadi, Bonia and Nike. In addition, electronic items such as Laptops, PS2s, MP3s and iPODs were also included in Picture A. The male respondents were found to be more likely to include electronic goods, mobile phones and sportswear in their drawings. In contrast, female respondents were found to be more likely to include, handbags, jewelleries and shoes in their drawings.

In contrast, the second picture - Picture B (a person without a lot of branded goods) was rather empty and all had no form of brand identification. Interestingly, the second drawing also contains items initially shown in Picture A such as shoes, house, clothing, mobile phone, watch and so on. However, all these items were drawn to look shabby, old and run down. For instance, 10 participants drew people with patchy old clothing; two respondents drew TV sets which were broken and, seven respondents drew rundown or wooden houses. Six participants wrote the word "poor" and three participants used the word "untidy" in their drawings of the person with no branded goods. There was no electronic media item in Picture B.

All drawings contained human figures. However, the "expression" on the human figures varies according to the requirements of the drawings. For example, participants were likely to draw a smiling face that corresponded to the statement about a person with a lot of branded goods. In Picture B however, all but one of the human figures sad or crying. One participant drew a human figure with a smiling face even though he did not have a pair of shoes.

Moreover, most participants in the study stayed true to their gender identification by drawing human figures that matched their own gender for both Picture A and Picture B. In fact, only one female participant drew a young boy to reflect to the statement of "a person without branded goods" in Picture B and a young girl Picture A "person with a lot of branded goods". It is thought this female that refused to associate the female with a negative value or negative personality traits. One female participant drew two human figures, that of a young girl and her mother with patchy clothing to correspond to Picture B. This respondent also accentuated the drawing with the following dyadic communication in speech balloons:

\footnotetext{
"Mum, why Mia does not have branded goods.. all of my friends have mobile phones and so on.."

"Well honey.. we are poor. I don't have enough money to buy you all such things.. my salary cannot afford to buy you all those branded goods."
}

On a similar note, 13 other participants attempted to capture in their drawing a sad person as someone without branded goods. These association were reflection the following monologues:

"I don't have much money to spend... I live in a shack.. I don't have new clothes.. I am a poor...I am an orphan..." (Male, 12)

"Why I'm wearing a patch shirt.. why I live in poverty.. I lost my parents.. I don't have money... I just live in an old cottage.." (Female,12)

All of the participants perceived a person with a lot of branded goods as cheerful. Basically, they thought that he/she would be cheerful because of his/her material contentment of having everything he/she wants and wishes as well as having satisfying family relations, as the following comments indicate:

He has "Acer" laptop, "Samsung" mobile phone and "Panasonic" TV (Male,11).

He has a lot of luxurious high tech gadgets such as laptop, MP3, "Nokia" mobile phone and a bungalow. He is also 
easy-going and approachable (Male, 12).

The opposite is true for those with no branded goods. In fact, the participants perceived a person without any branded items as poor, lazy, unfriendly, has bad manners and untidy. Both female and male participants had these negative thoughts and expressed them in the following comments:

She is poor and cannot afford to buy expensive things (Female,11).

He is poor, wears thorn shirts and doesn't have enough money (Female,11).

Furthermore, most of the participants perceived a person with a lot of branded goods as someone who would likely have more friends than the one without. This is reflected in Picture A where the rich person has lots of friends, is successful, possesses good manners, is helpful and humble.

This person (Picture A) is rich, has a lots of money, kind hearted, generous, and she is not arrogant (Female, 11).

The person in the first picture has various branded goods and many people love to make him

friend (Male, 10).

Clearly, from these descriptions, the young participants generally regard people with branded goods as having positive traits and characteristics. This view has been captured by a male participant who declared the following:

The young person in Picture A is successful, rich and has positive traits.

In contrast, only one participant perceived that the person in Picture A without a lot of friends. The 10 year old male boy noted:

The boy in the first picture is snobbish, demanding, not genuine and he has no friends.

In response to the question related to belongings and friends, $99 \%$ of the participants perceived a person without branded goods as less likely to find and attract friends. In fact, they noted that a person without branded goods has little to offer to other people and as such, are likely to be neglected by others:

This young person does not have branded goods and people always neglect her (Male, 10).

This is a poor boy, he is an orphanage and people do not like him (Female, 12).

In total, the participants used 53 behavioural characteristic to describe a person with a lot of branded goods and 40 for a person without branded goods. Most of the participants revealed that a person with branded goods is cheerful, smart, hard working, has good manners, and is sincere, active, sociable, helpful and responsible. In contrast, only a small number of participants associate a person with branded items with the negative characteristics of being crafty, cunning, showy, having bad manners, is arrogant and greedy. One-quarter of the 20 participants reported only positive behavioural characteristic with the remaining giving positive and as well as negative ones. Table II summarizes the characters in response to the question "What type of behaviour characters is associated with this person?"

As for Picture B, reflects the description given by the majority of the participants of the person without branded goods (Table III). Negative words such as lazy, unfriendly, gloomy, and jealousy were tagged to the person. Half of the participants (10) also used positive words like quite, sensitive, content, strong, humorous, smart, simple, having good manners and hardworking to refer to the person in Picture B. The following comments are referred to:

The girl in this picture is caring toward others. She is also very hardworking. She is lonely because all her friends do not want to play with her (Female, 10).

The girl here is simple and helpful. She is a bit old fashioned, pessimistic and unsociable like other people (Female, 11). Eight participants revealed these negative behaviour characteristic of Picture B, in the following:

He is a lazy person. He is unable to take care of himself and not respecting others (Male,10).

She is calculative, cowardly, ungrateful and an aggressive kind of person. People don't like her character (Female, 11).

Only two participants were reported to have used only positive behaviour characteristic on the person in Picture B.

She is a simple, helpful and hardworking person (Female,12).

This boy has good manners, is very helpful, hardworking and caring towards people (Male, 10).

Finally, in an attempt to assess their materialistic value direction, the participants were asked to determine who they would like to be - a person with branded goods or a person without branded goods. Twelve of twenty participants wanted to be the person in Picture A, while majority of the wanted to become wealthy, possess all kinds of expensive things and enjoy a happy life where they can buy anything they want. Also more male participants than females seemed to be more intent in wanting to be someone with a lot of possessions:

I want to have various branded goods, expensive items and be happy (Male, 10). 
I want to be a rich person who is kind hearted and generous (Male, 10).

One male participant however indicated his preference to be the person without branded items in Picture B. He perceives the person as one with a great personality even though he does not possess branded goods.

I want to be like the second picture because he is a caring boy, is helpful and hardworking (Male, 10).

Interestingly, a clear gender difference could be interpreted in participants' future aspiration. A total of eight female participants wanted to lead a moderate life, neither too rich nor too poor and they expressed a desire not to be arrogant when they grew up:

I choose to be moderate because I do not want people to label me as arrogant (Female, 11).

I want to be moderate because if I am a rich person, I become arrogant (Female, 12).

This study aims to discover the young consumer's perception involving picture drawing towards a person with or without possession of branded goods using a qualitative method. These young consumers are found to be brand conscious as they are able to recollect and represent in their drawings a large number of brand names and visual identification without any kind of support or prompting from the researcher. Many are found to be conversant with the brand names of the latest fashion as well as electronic gadgets. In fact, most of brands they mentioned are global brands like Nike, Adidas, Acer, Dell, and Nokia.

Analysis of the drawings unveils two noteworthy differences in children's perception about people with and without branded goods. Firstly, branded clothes differentiate the two groups. The participants acknowledge Nike and Adidas as their preferred trendy brands. They also associate modern technological gadgets like mobile phones and iPods as critical items that a brand conscious must person have. Together, these findings lend support to a much earlier finding reported by McNeal (1992). In his study, kids aged between four and twelve years olds were brand conscious when it comes to non-food products such as toys, clothes, records/cassettes, video games, sporting goods and cosmetics or toiletries. With regard to their perception of modern technological gadgets, the majority of the participants rate Nokia as the most impressive brand, followed by Sony Eriksson, Motorola and Samsung. Nokia's popularity among these young consumers is not at all surprising given Nokia's aggressive advertising campaign strategy targeting an audience ranging from kids to mature consumers. This clearly lend support to Goldberg and Gorn's (1974) contention that children in primary school can develop possessive attitudes for material goods by being exposed to tv commercials. There is a substantial body of research which indicates that television plays an important role in the socialization of children, especially concerning the source of product information (Reynolds and Wells, 1977; Rossiter, 1976).

Additionally, shoes are also rated as higher renowned goods by the participants with accordingly: Asadi, Bonia, Adidas, Nike, Bata and Oasis. Further analysis data shows that new electronic media tool such as the laptop is also highly rated by the participants as a must have for "a person with a lot of branded goods." In this instance, Acer is the most well-liked brand followed by Dell, HP and LG. It is possible that participants are familiar with these brands as they are not only exposed to many teaching aids in the classroom, but are also items normally purchased by their family members.

The second significant difference between a person with and without branded goods is reflected by the faces of the people drawn by the participants. None of the drawings of Picture A is sad or crying. The study found that a person with branded items is perceived as cheerful, happy and has more friends. This person is also likely to feel good about himself/herself. Parallel results are also obtained from the analysis. More specifically, a person with many branded goods is also perceived positive with the characteristic behaviour of being cheerful, smart and hardworking. On the contrary, participants associate the positive behaviour characteristic of being quiet, sensitive and content with people who are not brand conscious. Overall, these results are consistent with Chan's (2004) findings of children in Beijing.

These results demonstrate that children, even at a young age, are able to understand and articulate the value of belonging based on emotional attachment (having fun) and social meaning (ability to attract friends). Belonging is an essential criteria for children and perception of themselves and others.

In terms of materialistic value orientation, more than half of the participants express their desire for a life full of happiness, satisfaction and a high standard of living. Critically, a life such as this is undoubtedly associated with a person who uses branded goods. So essentially, this indicates that materialistic values are formed long before children reach their adolescent years, probably during the age span of eight to twelve. However, it is important to note that the children in this study tend to have mixed feelings about brand. While they seem to want to own branded items, one day, they are also aware of the negative connotations that they might have on their image. After all, a person with branded goods is often seem as crafty, cunning, arrogant and greedy. Understanding more about how children relate to brands, how they form conceptual meanings associated with brands and how they apply these brand meanings to make judgments about others would provide a sound basis for discussions about the impact of marketing to children. More attention is needed in brand marketing for education given recent criticisms of present strategies. 


\section{Conclusion}

The present study demonstrates that advertising efforts by marketers and manufacturers indeed influence children's knowledge, attitudes and values as it is mass media and advertising that provides information about consumption and the value of material goods (Atkin 1975b; Martin and Gentry 1997). The impact of these efforts as demonstrated in this study is reflected the young children's brand awareness and aspiration to own branded goods in their future. Furthermore, these children also show a complex understanding of what a brand represents. Understanding these issues is very essential to marketers who wish to reach the children. Also, marketers need to know where children get their information about consumer matters and how children respond to different consumer information sources. The mass media may be an important source of consumer information, but their significance may vary depending the type of product or service marketed. Other forms of promotional activities can be as effective under different circumstances, such as event sponsorship, school visits, and other forms of publicity. Events which are known to be popular with children may provide the ideal opportunity for building a positive feeling about not just brand names but also the friendliness of branded good owners.

This study, proposes the following hypothesis to test in a quantitative study:

H1: Children perceive the concept of branded goods by the time they reach about 10 to 12 years of age.

It is anticipated that the data collected through such a quantitative survey would not only be supportive in the examination of the link between perception of branded goods among children, but also with the development of consumer socialization during the analytical and reflective stages of the children's growth.

\section{References}

Achenreiner, Bachman, G., and John, D.R. (2003). The meaning of brand names to children: a developmental investigation. Journal of Consumer Psychology, 13 (3), 205-219.

Atkin, C. (1975). Effects of television advertising on children's and mothers' responses to television commercials, Report No.8, East Lansing:Michigan University, Department of Communication.

Belk, G.E., M.A. and Ceresino, G. (1985). Parental and teenage child influences in family decision making. Journal of Business Research, 13, 163-176.

Chan, K. (2004). Material world: Attitudes towards toys in China. Young Consumers, Vol. 6 No. 1, pp 54-65.

Dennis, W. (1966). Group Value Through Children's Drawings. John Wiley and Sons, New York, NY.

Goldberg, M.E., and Gorn, G.J. (1974). Children's reaction to television advertising: An experimental approach, Journal of Consumer Research, Vol. 1, pp.69-75.

Golomb, C. (1992), The child's creation of a pictorial world, University of California Press, Berkeley, CA., .

Goodenough, F.L. (1926). Measurement of intelligence by drawings, Harcourt, Brace and World, New York, NJ.

John, D.R. (1999). Consumer socialization of children: A retrospective look at twenty- five years of research. Journal of Consumer Research, 26, 183-213.

Martin, M.C. and James, W. G (1997). Stuck in the model trap: The effects of beautiful models in ads on female pre-adolescents and adolescents. Journal of Advertising, 26 (Summer), 19-33.

Matthews, J. (1999). The art of childhood and adolescence: The construction of meaning, Falmer Press, Philadelphia, PA.

McNeal, J.U. (1969). The child consumer: A new market. Journal of Retailing, Vol 45, pp. 15-22.

McNeal, J.U. (1992). Kids As Customers: A Handbook of Marketing to Children. Lexington Books, New York, NY.

Reynolds, F.D. and Wells, W.D. (1977). Consumer Behaviour. New York:McGrraw-Hill Book Company.

Rossiter, J.R. (1976). Visual and verbal memory in children's product information utilization. Advances in Consumer Research, Vol. 3 pp.523-7.

Thomas, G.V., Silk, A.M.J. (1990), An introduction to the psychology of children's drawings, New York University Press, New York, NY., .

Zaltman, G. (1997). Rethinking marketing research: Putting people back, Journal of Marketing Research, Vol. 34 pp.424-37. 
Table 1.Visual items in the drawings with branded goods

\begin{tabular}{|c|c|c|c|}
\hline $\begin{array}{c}\text { Image Components for Picture } A \\
\text { (Person with branded goods) }\end{array}$ & Freq̨uency & $\begin{array}{l}\text { Image Components for Fichute } B \\
\text { (Person without branded goods) }\end{array}$ & Freq̧uency \\
\hline Smiling face & 20 & Sadface & 18 \\
\hline Clothing & 20 & Money & 13 \\
\hline Mobile phone & 18 & Clothing & 10 \\
\hline Shoes & 17 & Shoes, Slippers & 8 \\
\hline Laptop & 15 & House & 7 \\
\hline Watch & 9 & Mobile phone & 5 \\
\hline Whllet and handbag & 9 & Watch & 2 \\
\hline Jewely & 8 & Beg & 2 \\
\hline TV set & 8 & $T V_{\text {set }}$ & 2 \\
\hline Money & 7 & Living near incinerator & 2 \\
\hline PS2 & 5 & Belt & 1 \\
\hline MP3 & 3 & Bicycle & 1 \\
\hline Eye glasses & 3 & Eye glasses & 1 \\
\hline Perfume & 3 & Living in an orphanage & 1 \\
\hline IPOD & 2 & & \\
\hline Cap & 2 & & \\
\hline Beit & 2 & & \\
\hline Make-up accessoties & 2 & & \\
\hline Friends & 1 & & \\
\hline Piano & 1 & & \\
\hline
\end{tabular}


Table 2. Behavior profile of a person with a lot of branded goods

\begin{tabular}{|c|c|c|c|}
\hline Pasitive Charactors & Frequency & Megative Charactoss & Frequency \\
\hline Cheerful & 18 & Crafty & 10 \\
\hline Smort & 16 & Cunning & 4 \\
\hline Hardworking & 16 & Showy & 4 \\
\hline Good manter & 16 & Following tnend & 4 \\
\hline Sincere & 15 & Bad manter & 3 \\
\hline Sindy hord & 15 & Arrogant & 3 \\
\hline Active & 14 & Greedy & 3 \\
\hline Sociable & 14 & Seek a life of pleasure & 2 \\
\hline Helpful & 14 & Calculative & 2 \\
\hline Responsible & 14 & Not respecting others & 2 \\
\hline Generous & 13 & Pessimistic & 2 \\
\hline Fair & 13 & Unsociable & 2 \\
\hline High solf-estem & 12 & Unicus & 2 \\
\hline Swollen & 12 & 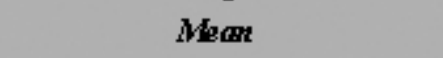 & 1 \\
\hline Thrift & 12 & Superficial & 1 \\
\hline Coring & 12 & Unable to take can of onesey & 1 \\
\hline Content & 11 & Aggressive & 1 \\
\hline Independent & 11 & Bad-tempered & 1 \\
\hline Srong & 11 & Spend extravagantly & 1 \\
\hline Optimstic & 10 & Sef-centered & 1 \\
\hline Easy-going & 10 & Lazy & 1 \\
\hline Cangul & 10 & Jeabous & 1 \\
\hline Forth sighted & 8 & Cowand & 1 \\
\hline High class & 7 & & \\
\hline Approachable & 7 & & \\
\hline Enjoy shopping & 7 & & \\
\hline Sympathetic & 6 & & \\
\hline Talkative & 6 & & \\
\hline Enjoy shopping & 5 & & \\
\hline Humorous & 5 & & \\
\hline
\end{tabular}


Table 3. Behaviour profile of a person without a lot of branded goods

\begin{tabular}{|c|c|c|c|}
\hline Poritive CPnrachrs & Frequensy & Wegntive Charactrs & Frequency \\
\hline Quits & 10 & $\operatorname{Lag} y$ & 14 \\
\hline Sensitive & 6 & Unthiendly & 13 \\
\hline Consint & 4 & Gloomy & 12 \\
\hline Strong & 4 & Jeniousy & 12 \\
\hline Bumoros & 3 & Oxf-ftsinon & 12 \\
\hline$S m a n$ & 3 & Unable to sike arye of one seif & 11 \\
\hline Simple & 3 & Ead manner & 11 \\
\hline Goof'minner & 3 & Ungratsul & 11 \\
\hline Hurdworking & 3 & Superflcial & 10 \\
\hline Shady hind & 3 & Wotrespecting obhers & 10 \\
\hline Symprohetic & 2 & Pessinistec & 9 \\
\hline Coreful & 2 & Conard & 9 \\
\hline Uriqus & 2 & Lonely & 9 \\
\hline Thoift & 2 & Bad-tempered & 8 \\
\hline Independent & 2 & Aggressive & 7 \\
\hline Active & 2 & Self-cengred & 7 \\
\hline Cheerful & 1 & Aggressive & 7 \\
\hline$E_{a g y-g \text { oing }}$ & 1 & Unsociable & 6 \\
\hline Caring & 1 & Mern & 5 \\
\hline Helpotul & 1 & Chlculative & 5 \\
\hline
\end{tabular}

